\title{
Intervenção em saúde do trabalhador com profissionais do sexo
}

\author{
Maria Altenfelder Santos², Ana Luiza Silva Fanganiello ${ }^{3}$ \\ Renata Paparelli ${ }^{4}$ e Fábio de Oliveira ${ }^{5}$
}

Faculdade de Psicologia da Pontifícia Universidade Católica de São Paulo

\begin{abstract}
A partir de um estágio em psicologia social do trabalho foi desenvolvida uma intervenção com profissionais do sexo na perspectiva da saúde do trabalhador. Tomando-se a prostituição como um trabalho, caracterizado pela situação de vulnerabilidade, buscou-se instaurar dentro do próprio local de trabalho (o bordel) um espaço de discussão entre as profissionais do sexo sobre temas relacionados à sua ocupação, visando à promoção de saúde das trabalhadoras. Em um total de dez encontros, foram abordadas questões referentes às formas específicas de organização desse trabalho, aos aspectos de vulnerabilidade, ao preconceito vivenciado e à maneira como os vínculos são estabelecidos nesse contexto. A intervenção mostrou-se potencializadora da apropriação de significados pessoais e coletivos pelas participantes, caracterizando-se como uma ferramenta para a ampliação da compreensão das trabalhadoras sobre suas próprias vivências, abarcando suas complexidade e ambigüidade.
\end{abstract}

Palavras-chave: Profissionais do sexo, Vulnerabilidade, Promoção de saúde, Análise do trabalho.

Health intervention with sex workers

Through an internship program, an intervention with sex workers was conducted, from the perspective of the worker's health. Taking prostitution as a job, characterized by its vulnerable situation, we sought to create within the work place (the brothel) a space for discussion, among the sex workers, on themes related to their occupation, with the aim of promoting the workers' health. With a total of ten meetings, issues was addressed concerning specific forms of organization for this type of work, its aspects of vulnerability, the prejudice experienced, and how bonds are established in that context. By helping the participants to retrieve their personal and collective meanings, this intervention has proved to be an empowering tool for the promotion of a deeper awareness and broadening the understanding of workers on their own experiences, covering their complexity and ambiguity.

Keywords: Sex workers, Vulnerability, Promotion of health, Analysis of work.

\section{Introdução}

experiência apresentada a seguir ocorreu no contexto das atividades de estágios em
psicologia do trabalho da graduação em psicologia da Faculdade de Psicologia da
Pontifícia Universidade Católica de São Paulo. A intervenção realizada teve como ponto de
partida a reflexão de uma das estagiárias sobre o tipo de atendimento oferecido a uma
determinada categoria de trabalhadoras, as profissionais do sexo, em um Centro de
Orientação e Aconselhamento Sorológico (COAS) localizado na cidade de São Paulo,

1 Uma versão preliminar deste artigo foi apresentada durante o XIV Encontro Nacional da Associação Brasileira de Psicologia Social, "Diálogos em Psicologia Social", em novembro de 2007.

2 Psicóloga pela Pontifícia Universidade Católica de São Paulo. Mestranda em psicologia social pelo Instituto de Psicologia da Universidade de São Paulo.

3 Aluna do curso de psicologia da Pontifícia Universidade Católica de São Paulo.

4 Docente da Faculdade de Psicologia da Pontifícia Universidade Católica de São Paulo. Doutoranda em psicologia social pelo Instituto de Psicologia da Universidade de São Paulo.

5 Docente da Faculdade de Psicologia da Pontifícia Universidade Católica de São Paulo. Psicólogo do Centro de Psicologia Aplicada ao Trabalho do Instituto de Psicologia da Universidade de São Paulo. Doutor em psicologia social pela PUC-SP. 
serviço vinculado ao Programa Estadual de DST/Aids de São Paulo e à Secretaria Estadual de Saúde de São Paulo.

Nesses atendimentos, configurados como aconselhamentos individuais ligados à prevenção de DST/Aids, constatou-se que muitas das profissionais traziam a demanda por um espaço de escuta ampliado que pudesse acolher suas vivências no ofício. A partir disso, foi desenvolvido um projeto de intervenção, sob a perspectiva da saúde do trabalhador, com uma equipe de duas estagiárias e dois supervisores ${ }^{6}$.

A proposta foi fundamentada no entendimento das profissionais do sexo enquanto trabalhadoras, assumindo-se um posicionamento crítico ao julgamento moral da prostituição. Segundo Bila Sorj:

abordar o universo da prostituição como um mundo de relaçães de trabalho e, por conseguinte, a prostituta como mulher trabalhadora (...) [é uma escolha que] já contém em si mesma uma crítica avassaladora ao modo como usualmente as prostitutas são tratadas: vítimas, libertinas, marginais... (...). Mesmo que esta nova concepção ainda não seja predominante, nem no conjunto da categoria nem na sociedade, ou mesmo que sua institucionalização possa sofrer idas e vindas, a percepção da prostituta como trabalhadora já faz parte do léxico político atual. E será certamente com ela que as feministas, a Igreja, os poderes públicos, o sindicalismo, para citar apenas algumas instituições, terão que dialogar daqui para frente (Sorj, 1995, pp. 9-10).

A perspectiva da saúde do trabalhador está vinculada ao campo da saúde pública. Segundo Dias e Mendes (1991), essa corrente surge em meio a um intenso processo de transformação social, ocorrido no mundo ocidental a partir do fim da década de 60, crítico aos modelos centrados na assistência médica, hegemônicos nas práticas de atenção à saúde dos trabalhadores.

Dias e Mendes (1991) descrevem a saúde do trabalhador como um campo interdisciplinar, que investe na possibilidade de articulação entre conhecimento prático (dos trabalhadores) e teórico (dos técnicos), de maneira a instaurar um espaço de construção coletiva das formas de enfrentamento dos problemas vivenciados no cotidiano de trabalho implicados no processo saúde-doença.

Nessa perspectiva, Dejours (1992) propõe como estratégia de intervenção, visando à promoção de saúde, a constituição de espaços de discussão nos próprios locais de trabalho. $\mathrm{O}$ autor sugere uma ação de escuta e interpretação do conjunto de trabalhadores, com o foco sobre o trabalho. Dejours (1992) entende que a palavra, bem como as demais formas de expressão que possam emergir no espaço de discussão, constituem o material a partir do qual se pode apreender tanto a experiência concreta quanto a representação da vivência subjetiva do coletivo. O trabalho apresentado a seguir foi, em parte, inspirado nessas idéias.

A pesquisa bibliográfica revelou a escassez de estudos na abordagem da saúde do trabalhador voltadas particularmente à categoria de profissionais do sexo. Trata-se de uma categoria de trabalhadoras bastante peculiar. Seu trabalho é caracterizado por grande vulnerabilidade, na medida em que as profissionais estão constantemente expostas a riscos de sofrerem diferentes tipos de violência, uso de álcool e drogas, infecção por DSTs (doenças sexualmente transmissíveis), discriminação social, entre outros.

A noção de vulnerabilidade tem se consolidado como um instrumento fundamental no campo da saúde pública. Ayres (1996) descreve o surgimento dessa noção na área da prevenção como forma de superação do referencial epidemiológico, baseado em conceitos discriminatórios como fatores, grupos ou comportamentos de risco. Ayres (1996) critica o fato de que esses conceitos abstraiam as determinações sociais e políticas dos fenômenos de 
adoecimento, culpabilizando indivíduos e impedindo o diálogo necessário entre serviços e público-alvo. Já no conceito de vulnerabilidade, segundo o autor, está contemplada uma síntese entre as dimensões sociais, políticas, institucionais e comportamentais, associadas às diferentes suscetibilidades de indivíduos ou grupos ao adoecimento. Isto é, nessa abordagem, não se trata de distinguir aqueles que têm alguma chance de adoecer, mas de avaliar as diferentes chances que todo indivíduo possui de maior exposição ou menor proteção diante do problema, de acordo com características de seu cotidiano individual e social.

O Documento referencial para ações de prevenção das DST e da Aids, voltado às profissionais do sexo e publicado pelo Ministério da Saúde em 2002, contribui com a caracterização da situação de vulnerabilidade dessas trabalhadoras, discutindo a alta complexidade da atividade que exercem, na medida em que esta é permeada pela construção sócio-histórica de valores morais referentes à questão da sexualidade.

Segundo o Ministério da Saúde (2002), o preconceito mostra-se presente de maneira ambígua nesse contexto, pois a profissional é vista (e ela própria se vê) ora como vítima impotente, sem alternativas diante de uma condição de miséria econômica, ora como culpada por sua atividade sexual transgressora aos padrões vigentes.

A prostituição é, assim, insistentemente identificada com o território da marginalidade, da clandestinidade. A estigmatização, por sua vez, perpetua esse círculo vicioso de exclusão, impossibilitando o acesso à condição de cidadania pela profissional do sexo, na medida em que ela própria incorpora sua invisibilidade enquanto sujeito social (Ministério da Saúde, 2002).

\section{Objetivos}

O intuito da intervenção foi proporcionar um espaço de discussão e reflexão entre profissionais do sexo sobre os temas relacionados ao trabalho e à saúde, enfocando a dimensão subjetiva de sua atividade. Partindo da perspectiva da saúde do trabalhador, entende-se o dispositivo grupal como um instrumento de promoção de saúde, na medida em que contribui para o enfrentamento coletivo das dificuldades vivenciadas no cotidiano de trabalho.

\section{Metodologia}

A intervenção ocorreu entre os meses de setembro e novembro de 2006. A princípio, planejou-se a realização de encontros com profissionais do sexo que fossem usuárias do COAS de um determinado bairro da cidade de São Paulo ou trabalhadoras das proximidades, a serem convidadas pelas estagiárias. No entanto, quando a proposta foi apresentada a uma das usuárias e possível participante, dona de um bordel localizado na mesma região, ela levantou a possibilidade de realizar o grupo em seu próprio local de trabalho.

A intervenção ocorreu, então, nesse bordel, totalizando dez encontros, de aproximadamente uma hora de duração, com a participação voluntária das trabalhadoras do local. Compareceram a cada encontro de uma a quarto participantes. A proposta dos encontros, coordenados pelas estagiárias, era de que as profissionais do sexo falassem livremente sobre o seu trabalho. 


\section{Resultados}

\section{Descrição do local de trabalho}

O bordel localiza-se em uma rua paulistana de comércio popular, movimentada durante o dia e mais vazia durante a noite. A fachada é pintada de roxo, com um toldo roxo sobre a pequena porta. Logo na entrada há um capacho com ideogramas japoneses e, em destaque, a palavra "amor" em português. Em seguida há uma escada e, no meio do caminho, um portão com grades e uma corrente com cadeado. Nessa escada já havia um cheiro forte, indecifrável, que acompanhou as estagiárias ao longo do trabalho. Subindo os degraus vermelhos e desgastados, o visitante depara-se com um grande espelho inclinado, que reflete todo o salão, tornando os recém chegados visíveis a quem estiver presente no recinto e viceversa. Ao lado desse espelho há uma grande foto de propaganda de uma revista masculina. Outro cartaz que estava logo ao lado chamou muito a atenção, pois, ainda em setembro, trazia a figura de um grande Papai Noel tomando um refrigerante e enunciando a frase "a magia é para todos".

Do lado esquerdo de quem entra há um pequeno palco espelhado. Logo ao lado está o bar com uma decoração peculiar: CDs colados na parede, bebidas em prateleiras de vidro, um balcão preto e uma pequena placa ao centro do bar com os dizeres "Deus fez o mundo, Eva fez o pecado, Adão fez o dinheiro, o Diabo fez o fiado". Na outra parede há uma janela e logo abaixo um sofá antigo, ao lado de um caça-níqueis. Do outro lado da sala há uma jukebox.

Todas as paredes do salão são revestidas por um tapume de madeira, as pequenas mesas espalhadas pelo salão são pretas e cada uma contém de duas a três cadeiras inteiramente revestidas de couro sintético preto. Os encontros do grupo de profissionais do sexo com as estagiárias de psicologia foram realizados nesse local. Por todo o salão existem arranjos com flores artificiais vermelhas. E no teto por vezes objetos decorativos estavam pendurados, por ocasião de alguma comemoração específica (aniversários, por exemplo). Fixadas no alto, duas televisões transmitem as imagens de DVDs comuns e pornográficos. Bem no meio do salão fica uma mesa de bilhar, que por vezes foi usada pelas profissionais do sexo como cama fora do horário de trabalho.

Há também, no fundo do salão, do lado oposto da janela, uma saleta sem porta com a parede de espelho e uma mesa com duas cadeiras, transmitindo a sensação de um local mais reservado. Ao lado dessa saleta, um corredor dá acesso a quatro quartos e a uma grande sala sem janelas, iluminada por luz verde. À direita fica a cozinha.

Mesmo não tendo entrado nos quartos, perceberam-se algumas de suas características, as paredes eram feitas de divisórias, sem janelas e sem forro. Os quartos eram pequenos e também iluminados pela mesma luz verde. Em frente aos quartos há um pequeno escritório que contém uma mesa, caixas de cervejas e um grande quadro com a figura de Cristo.

\section{Organização do trabalho}

Notamos que uma das grandes motivações para o trabalho das "garotas" (como elas fizeram questão de serem chamadas: "profissionais do sexo você deixa para seus professores, aqui é garota de programa") é financeira. Segundo o que elas relatam às estagiárias, "o dinheiro é rápido e não é fácil" e é de fundamental importância para sua sobrevivência e o sustento de seus filhos. Em uma noite de muito trabalho pode-se ganhar o valor correspondente a um mês 
atuando como empregada doméstica ou atendente de lanchonete. De forma que, nessa profissão, o volume de dinheiro recebido é muito maior do que a remuneração de qualquer outro emprego em que elas já trabalharam ou que consideram como uma possibilidade de trabalho. Em uma noite de trabalho, uma "garota" pode chegar a ganhar cerca de duzentos reais fazendo dez programas.

As "garotas" contam, ainda, com aparente flexibilidade do trabalho, como poder rejeitar um cliente, estabelecer seu próprio ritmo e suas próprias regras dentro do quarto, como: "só beijo na boca de cliente bonito". Na casa onde foi realizada a intervenção havia uma exigência de que em cada programa fossem incluído "um sexo oral e um vaginal", pagos antecipadamente à dona do estabelecimento, sendo que uma parte dessa quantia seria destinada à profissional. As demais combinações eram feitas à parte, entre o cliente e a "garota". A principal fonte de renda da casa é o comércio de bebidas, por isso, faz parte do contrato com cada "garota" que ela estimule o consumo, sendo que para tanto recebe uma porcentagem do lucro. Toda a bebida consumida, tanto por elas, como pelos clientes é paga por este últimos.

Outras regras de funcionamento da casa estipuladas pela proprietária são: não beijar o cliente no salão, não portar nem fazer uso de drogas ilícitas dentro da casa, ausentar-se da casa por no máximo vinte minutos durante o período de trabalho, que vai das dezoito horas até o último cliente. No caso de não cumprimento das regras, as "garotas" poderiam ser multadas a critério da dona do estabelecimento.

O rigor das regras aumenta quando se trata de drogas ilícitas, pois isso implica em um risco para a dona do estabelecimento. Ela conta que, se achar necessário, faz uma "operação pente fino" à procura de drogas: "se eu for para cadeia por menina que está passando droga aqui dentro eu mato ela, ela vira peneira". Ela conclui esse pensamento falando ainda que prefere ser presa por dar trabalho para uma menor de idade que falsificou seu documento para garantir seu sustento, a ser pega por drogas, coisa que ela abomina. Embora possa ser presa por aliciamento de pessoas, ela contorna essa situação através de propinas. Ainda assim, há o risco permanente de denúncia, o que pode resultar no fechamento da casa e na prisão da proprietária.

\section{Vulnerabilidade}

Todas as profissionais dessa instituição provavelmente fazem ou já fizeram uso de drogas, lícitas ou ilícitas, como relatou uma das "garotas", que diz ter feito uma enquete com todas as profissionais que passaram pela casa. Diariamente fazem uso de álcool, tendo esse consumo uma função diretamente ligada à atividade de trabalho, tanto no sentido dos lucros, quanto para se sentirem encorajadas a realizarem os programas, pois, como relatou uma das trabalhadoras, "ser penetrada por uma pessoa que você não conhece é muito difícil".

Elas dizem que seu trabalho "é um serviço público... é público por que qualquer um pode entrar", o que significa estarem expostas a desconhecidos, correndo o risco de serem alvo de violência. Risco que se busca minimizar com as medidas de proteção tomadas pela casa, como ter seguranças contratados e as paredes dos quartos vazadas, o que diminui a privacidade, mas garante maior segurança.

Para evitar o risco de contaminação por DSTs todas relatam que não abrem mão do uso de preservativos, apesar de declararem que o número de preservativos distribuídos pelo sistema público de saúde é insuficiente: "esses homens que vêm no bordel e querem transar sem camisinha, eu desconfio, eles não sabem se eu tenho doença ou não. Esses homens têm doença". A própria dona do estabelecimento incentiva as garotas a estarem sempre alertas para o uso de preservativos e para que seus clientes não o retirem sem que elas percebam, pois o corpo é percebido como instrumento de trabalho. Uma das falas que demonstra essa preocupação é: 
"eu não quero pegar doença nem do meu namorado, que eu gosto, muito menos de um desconhecido".

A maioria das profissionais são usuárias do centro de saúde local e do COAS, onde fazem exames (HIV, sífilis, hepatite) a cada quatro meses e recebem setenta preservativos por mês, o que não supre a demanda, pois, como apontado acima, algumas chegam a fazer dez programas por noite. Porém, ao questionar-se uma das "garotas" sobre como cuidava da sua saúde, ela respondeu que deixava "na mão de Deus".

\section{Preconceito}

A dificuldade de essa profissão ser reconhecida parece girar em torno da questão do preconceito. De acordo com o que vivenciamos ao longo do trabalho, o preconceito está presente em todas as relações: com o cliente, com a sociedade em geral, no meio acadêmico e inclusive partindo das próprias profissionais.

Todas fazem uso de um pseudônimo para se identificar dentro do local de trabalho e esse nome é trocado conforme a casa em que estão exercendo a atividade, facilitando assim o anonimato, que é considerado fundamental no ofício em função do preconceito vivido por elas.

Elas contam que às vezes acontece de serem xingadas na rua por clientes que já usufruíram de seus serviços. Apesar de serem uma minoria, há clientes que as maltratam verbal e fisicamente durante o trabalho e fora. As profissionais relatam esconder sua profissão da maioria das pessoas, principalmente de suas famílias: "meu filho não vai saber que eu sou garota de programa... eu não tenho vergonha, mas também não tenho orgulho... é um trabalho como outro, mas não é aceito". Apesar de dizerem que consideram essa uma profissão como outra qualquer, afirmam que não gostariam de ser registradas: "eu não quero uma carteira de trabalho escrito 'prostituta'".

A religião reforça uma ambigüidade de sentimentos, gerando culpa por exercerem uma atividade considerada pecaminosa: "tem até um dos dez mandamentos que diz 'não se prostituirás'". Outra frase marcante no sentido dessa culpabilização gerada pela religião é: "toda vez que um homem sai de cima de mim, eu rezo".

Há ainda o preconceito das próprias "garotas" contra um tipo que chamam de "a puta de paredão", referindo-se a mulheres que fazem sexo por prazer e com muitos parceiros, em suas palavras: "a mina que vai na balada e transa com qualquer um, acha o cara da balada bonitinho, vai com ele para o motel e não cobra". Essas não seriam profissionais, mas mulheres promíscuas.

Durante o estágio, sentíamos que estávamos adentrando um território muito delicado, tocando em alguns tabus da sociedade. Percebemos que o tema por várias vezes gerou discordâncias e incômodos. No meio acadêmico que freqüentamos, deparamo-nos com reações que variaram do interesse ou da curiosidade à repulsa.

No início da relação com as estagiárias, as "garotas" pareciam testá-las, perguntando se estavam preparadas para ser confundidas com uma delas ao saírem da boate. Ao mesmo tempo, valorizavam a presença das estagiárias ali. Ao final do trabalho, mostraram de maneira clara a segregação que vivenciavam, caracterizando "o mundo lá fora e o mundo aqui dentro", como se houvesse uma barreira entre elas e o resto da sociedade. A dona da casa disse que nunca havia visto uma intervenção desse tipo "em dez anos de noite" e que o fato de as estagiárias escutarem o que elas tinham a dizer sem julgá-las já era uma forma de romper com essa barreira, pois as conversas possibilitavam levar para "fora" um pouco do que a equipe vivenciou lá dentro, mostrando que elas são pessoas comuns, o que poderia ajudar a combater um pouco do preconceito. 


\section{Vínculos}

As maiores dificuldades encontradas na intervenção estavam ligadas à maneira como os vínculos são estabelecidos pelas profissionais. Ao mesmo tempo, foi através dessas dificuldades que se pôde analisar os sentidos de todo o nosso trabalho.

Desses vínculos, o que mais chamou a atenção foi a sua característica de ambigüidade, presente em todos os momentos, inclusive na relação com a equipe de intervenção. Por vezes, as estagiárias foram tratadas como pessoas "do bem", "legais" ou "simpáticas". Por outras, eram encaradas como invasoras e curiosas, pessoas que não estavam lá para prestar um serviço, mas sim em função de uma mera curiosidade pelo exótico. Diversas vezes a equipe foi advertida, de maneira sutil, da experiência anterior que haviam tido com outros "pesquisadores". Relataram que um grupo de estudantes de comunicação esteve na casa para fazer uma pesquisa sobre a vida das prostitutas, a partir de um questionário "invasivo", segundo elas. As entrevistas foram filmadas e remuneradas. Ao final, prometeram que retornariam para mostrar o vídeo, mas nunca voltaram. Esse episódio caracterizou de modo marcante uma repetição da relação comercial com o cliente, que vem, satisfaz-se, paga e desaparece. Em todos os encontros, a equipe teve que reafirmar seu objetivo, dizendo que não estava lá por simples curiosidade, mas para fazer uma intervenção conjunta com elas, buscando criar momentos de conversa e de troca de experiências.

Toda vez que as estagiárias chegavam, tinham a sensação de que estavam ali pela primeira vez. Eram recebidas com surpresa, mesmo com a já habitual freqüência semanal dos encontros e no mesmo horário. Após o primeiro encontro, que contou com a participação da dona da casa e de mais três profissionais, o grupo realizou-se com um número menor de participantes efetivas, ainda que várias "garotas" participassem de maneira indireta, rondando o grupo e às vezes fazendo algum comentário ou simplesmente escutando.

Desde o primeiro dia, a proprietária do estabelecimento ressaltou que, após o contato intermediado pelo COAS, não acreditava que a proposta fosse levada adiante e disse a uma das estagiárias: "estou gostando de ver, você está levando isso em frente". Essa estagiária era uma referência para as "garotas", que esperavam encontrá-la também no COAS, o que afirmaram diversas vezes. Inclusive, na ocasião em que uma "garota" deixava a casa definitivamente, ela disse à estagiária: "vou te procurar lá no posto pra gente conversar".

No primeiro encontro, uma das "garotas" questionou se seria obrigatório revelar seu nome verdadeiro e foi-lhe dito que isso não era necessário. Em outro encontro, essa mesma profissional revelou às estagiárias, de maneira sutil e com cumplicidade, seu nome, enquanto contava que seu ex-marido o havia tatuado na própria mão. Ao final, ela foi despedir-se e falou "muito prazer" e riu por ter falado isso, pois não era a primeira vez que via as estagiárias. Então, uma das estagiárias respondeu: "não deixa de ser muito prazer, afinal foi hoje que você me falou seu nome, né?". Imediatamente a outra "garota" que havia participado do grupo aproximou-se e disse: "eu posso falar meu nome também?". Consideramos isso um gesto de confiança.

É notável a alta rotatividade de profissionais na casa. Quando teve início a intervenção, havia oito moradoras fixas, além de quatro outras "garotas" que também trabalhavam no local. Ao longo dos três meses, esse quadro funcional modificou-se constantemente, sendo que ao final havia apenas duas moradoras remanescentes daquelas que estavam no início. Atribuímos essa situação à dificuldade de serem mantidas relações estáveis na profissão, seja com as pessoas, seja com os estabelecimentos de trabalho. Em alguns momentos, as estagiárias sentiram-se pessoalmente desprezadas, como se sua presença ali não fizesse diferença. Houve uma situação em que a "garota" que participou mais efetivamente dos grupos e envolveu-se com as discussões estava indo embora definitivamente da casa. Por acaso as duas estagiárias a encontraram na hora em que ela estava saindo. Ela 
disse que não ficaria para o grupo, alegando que não poderia mais permanecer na casa e mal despediu-se.

Por vezes, as estagiárias depararam-se com clientes na casa, ainda que houvesse um combinado de que naquele horário o estabelecimento não funcionaria. Como em um dia em que a equipe chegou e dois clientes estavam no sofá. Não havia mais ninguém no salão. As estagiárias perguntaram pela proprietária e eles responderam maliciosamente: "senta aqui, ela já vem". Foi a primeira vez que as psicólogas foram claramente confundidas com "garotas", o que lhes casou certo embaraço. Embora imaginássemos que essa situação pudesse ocorrer, naquele momento deparamo-nos com a frustração de um rompimento do contrato e de uma desconsideração para com a presença da equipe.

Até que começamos a entender a enorme dificuldade de romper com um padrão de relação no qual todos são tidos como exploradores e descartáveis. Isso foi algo que as estagiárias vivenciaram na prática. Por vezes, sentiam-se tratadas como clientes: "hoje não tem garotas pra vocês, meninas", disse uma vez a proprietária. Em três ocasiões a reunião não aconteceu porque a casa estava para começar suas atividades. Ainda assim, insistiu-se em continuar o trabalho, redefinindo-se o enquadre de forma clara e analisando-se que a maneira como os acordos era quebrados revelava os tipos de relação e de compromissos possíveis de serem estabelecido por elas.

Algumas características das relações entre elas ficaram evidenciadas nas falas sobre a rivalidade e a desconfiança, o que foi citado apenas nos últimos encontros. Elas estão em permanente estado de alerta, como se de alguma maneira estivessem sendo traídas em tempo integral pelas colegas de trabalho, seja pela disputa por clientes ou pelas intrigas que podem até levar a agressões físicas. Há uma tensão constante inclusive nos momentos de descanso: "eu durmo com um olho aberto e outro fechado".

As brigas que terminavam em facadas eram relatadas freqüentemente, mostrando que a faca é um instrumento de proteção, bem como de prática da violência, como se pode ver na frase: "tenho uma faca em cima do meu guarda-roupa", dita por uma "garota" enquanto relatava sua sensação de insegurança diante dos clientes.

A relação com os clientes é muito contraditória. Ao mesmo tempo em que dizem frases do tipo: "o único prazer que eu tenho é quando me pagam", "não tem nada de bom neste trabalho", "não há prazer em dar para um cara e, depois de meia hora, dar para outro", "ele me comeu e depois foi comer outra... eu sei que o que eu falei foi estranho, mas é isso que falamos aqui, é assim mesmo" (situação em que é usufruída como se fosse um objeto), também falam sobre um outro lado da relação com os clientes: "oitenta e nove porcento dos clientes que vêm aqui nos tratam muito bem" ou "o cara me trata como uma princesa, melhor que meu namorado". Relatam que muitos clientes são carinhosos, carentes e que em alguns casos vêm à procura de companhia ou da realização de fetiches. Por exemplo, uma das participantes contou que, quando estava grávida e trabalhando, era rejeitada por alguns clientes, porém outros vinham à sua procura e pagavam pelo programa "muitas vezes só para passar a mão na minha barriga".

Freqüentemente as "garotas" sentem-se envolvidas pelos clientes, chegando a imaginar que daqueles momentos fugazes pode surgir um relacionamento duradouro e estável. Isso, muitas vezes, é incentivado pelo próprio cliente, que faz promessas e dá presentes. Algumas "garotas" de fato deixaram a profissão para casarem-se com ex-clientes, o que alimenta o sonho de muitas. Ao mesmo tempo em que relatam esse desejo de serem resgatadas desse abismo relacional, valorizam acima de tudo sua independência e parecem estar preparadas para, a qualquer momento, serem descartadas. Essa ambigüidade também fica visível quando falam sobre casamento, algo que, em um mesmo enunciado, idealizam e rejeitam: "o cara que me tirar daqui vai ser pra casar de véu e grinalda" e, poucas frases depois: "eu não vou casar, não vou depender de homem". 
Existe, ao mesmo tempo, um pensamento de que "uma vez na noite, sempre na noite", como se não houvesse a possibilidade de rompimento com esse modo de vida: "ou a menina casa por dinheiro e trai por amor, ou casa por amor e trai por dinheiro". Nesse sentido, o desejo de viver um romance (como relatou uma profissional mais antiga) é tido como uma "ilusão infantil". Seria necessário desfazer-se de fantasias românticas. Isso revela que a profissão exige uma adaptação das formas pessoais de relação de quem a exerce, o que representa um impacto considerável sobre as vidas afetivas dessas trabalhadoras.

Os filhos são a única fonte de entrega desinteressada a uma pessoa. Seu sustento é uma motivação primordial para manterem-se no trabalho: "eu quero trabalhar para comprar uma casa para o meu filho, para ele ter um lugar para morar e não ter que se humilhar como eu". Apesar disso, a maioria mantém-se afastada dos filhos, seja para ocultar o trabalho, seja por outras razões.

\title{
Considerações finais
}

Apesar do curto período da intervenção, o espaço de reflexão grupal mostrou-se potencializador da apropriação de significados pessoais e coletivos pelas participantes. Dessa forma, a proposta caracterizou-se como uma ferramenta para a ampliação da compreensão dessas trabalhadoras sobre suas próprias vivências complexas, conflituosas e ambíguas.

A partir da sugestão do trabalho como tema disparador, inúmeros assuntos foram abordados. Na fala das profissionais, a ambigüidade aparece repetidamente como característica da atividade. Discurso ambíguo que, longe de expressar falta de clareza de raciocínio, revela o modo como essa ambigüidade está presente na realidade. Nas palavras de Chaui (1996):

\begin{abstract}
ora, seres e objetos culturais nunca são dados, são postos por práticas sociais e históricas determinadas, por formas de sociabilidade, da relação inter-subjetiva, grupal, de classe, da relação com o visível e o invisível, com o tempo e o espaço, com o possível e o impossível, com o necessário e o contingente. Para que algo seja isto ou aquilo e isto e aquilo é preciso que seja assim posto ou constituído pelas práticas sociais (...) Ambigüidade não é falha, defeito, carência de um sentido que seria rigoroso se fosse unívoco. Ambigüidade é a forma de existência dos objetos da percepção e da cultura, percepção e cultura sendo, elas também, ambíguas, constituídas não de elementos ou de partes separáveis, mas de dimensões simultâneas (p. 122).
\end{abstract}

A situação de vulnerabilidade evidencia-se na recorrência dos temas ligados ao uso diário de drogas lícitas ou ilícitas, ao risco de sofrerem violência física e aos preconceitos, que se mostram presentes em todas as relações (com o cliente, com a sociedade em geral, com as próprias colegas de profissão). As estratégias utilizadas para lidar com essas dificuldades também são citadas.

Além disso, as relações estabelecidas nesse contexto são muito íntimas e, ao mesmo tempo, fugazes. Pôde-se constatar a fragilidade dos vínculos estabelecidos pelas profissionais do sexo, referente não apenas às suas relações interpessoais, mas também à vinculação com o local de trabalho: notou-se uma acentuada rivalidade entre as colegas de trabalho e a alta rotatividade das trabalhadoras no estabelecimento, o que se refletiu nos encontros com as estagiárias.

Diante desses obstáculos para a constituição do grupo, pôde-se analisar o quanto essas manifestações eram próprias dessa forma específica de organização do trabalho. Reproduziam-se, na dinâmica grupal, as impossibilidades vividas cotidianamente por aquelas 
trabalhadoras, como, por exemplo, manter compromissos, romper com determinados padrões de relação, sair de um permanente estado de alerta e desconfiança, elaborar conteúdos ambíguos que marcam constantemente o exercício da atividade.

Ao término do processo, essas questões foram retomadas em um encontro de devolutiva e avaliação da experiência, no qual as estagiárias e as participantes consideraram a relevância da intervenção realizada, bem como a importância de sua continuidade.

Acredita-se que essa intervenção tenha a contribuir para a construção de formas de atuação que busquem dimensionar o impacto subjetivo da atividade das profissionais do sexo, bem como as possibilidades de intervenção sobre essa realidade. Entende-se que essa proposta é uma dentre as ações possíveis tendo em vista o desenvolvimento de dispositivos de intervenção com profissionais do sexo que visem, no longo prazo, a contribuir com a garantia de maior eficácia das ações voltadas ao atendimento à saúde integral dessa população, diminuir a vulnerabilidade a que estão expostas essas trabalhadoras e promover a cidadania das profissionais do sexo.

\section{Referências}

Ayres, J. R. de C. M. (1996). HIV/Aids, DST e abuso de drogas entre adolescentes: vulnerabilidade e avaliação de ações preventivas. São Paulo: Casa de Edição.

Brasil. Ministério da Saúde (2002). Profissionais do sexo: documento referencial para ações de prevenção das DST e da Aids (Série Manuais, no 47). Brasília: Ministério da Saúde.

Chaui, M. (1986). Conformismo e resistência: aspectos da cultura popular no Brasil. São Paulo: Brasiliense.

Dejours, C. (1992). A loucura do trabalho: estudo de psicopatologia do trabalho (5⿳亠丷厂 ed. ampliada). São Paulo: Cortez e Oboré.

Mendes, R. \& Dias, E. C. (1991). Da medicina do trabalho à saúde do trabalhador. Revista de Saúde Pública, 25 (5), 341-349.

Sorj, B. (1995). Prefácio. In A. F. Moraes (Org.), Mulheres da Vila: prostituição, identidade social e movimento associativo. Petrópolis: Vozes.

\section{Endereço para correspondência:}

marialtenfelder@gmail.com, anafanganiello@gmail.com,rpaparel@uol.com.br, faboli@uol.com.br 